\title{
Differential Sensitivity of Two Endothelial Cell Lines to Hydrogen Peroxide Toxicity: Relevance for In Vitro Studies of the Blood-Brain Barrier
}

\author{
Olufemi Alamu ${ }^{1,2} \mathbb{D}$, Mariam Rado ${ }^{1}$, Okobi Ekpo $^{1}$ and David Fisher ${ }^{1, *(\mathbb{C})}$ \\ 1 Department of Medical Bioscience, University of the Western Cape, Bellville, Cape Town 7530, South Africa; \\ olufemialamu@gmail.com (O.A.); maryamadem99@gmail.com (M.R.); oekpo@uwc.ac.za (O.E.) \\ 2 Anatomy Department, Ladoke Akintola University of Technology, Ogbomoso 210241, Nigeria \\ * Correspondence: dfisher@uwc.ac.za; Tel.: +27-21-959-2185
}

Received: 28 October 2019; Accepted: 6 January 2020; Published: 10 February 2020

\begin{abstract}
Oxidative stress (OS) has been linked to blood-brain barrier (BBB) dysfunction which in turn has been implicated in the initiation and propagation of some neurological diseases. In this study, we profiled, for the first time, two endothelioma cell lines of mouse brain origin, commonly used as in vitro models of the blood-brain barrier, for their resistance against oxidative stress using viability measures and glutathione contents as markers. OS was induced by exposing cultured cells to varying concentrations of hydrogen peroxide and fluorescence microscopy/spectrometry was used to detect and estimate cellular glutathione contents. A colorimetric viability assay was used to determine changes in the viability of OS-exposed cells. Both the b.End5 and bEnd. 3 cell lines investigated showed demonstrable content of glutathione with a statistically insignificant difference in glutathione quantity per unit cell, but with a statistically significant higher capacity for the b.End5 cell line for de novo glutathione synthesis. Furthermore, the b.End5 cells demonstrated greater oxidant buffering capacity to higher concentrations of hydrogen peroxide than the bEnd. 3 cells. We concluded that mouse brain endothelial cells, derived from different types of cell lines, differ enormously in their antioxidant characteristics. We hereby recommend caution in making comparisons across BBB models utilizing distinctly different cell lines and require further prerequisites to ensure that in vitro BBB models involving these cell lines are reliable and reproducible.
\end{abstract}

Keywords: oxidative stress; blood-brain barrier; bEnd5; bEnd.3; glutathione; viability

\section{Introduction}

The blood-brain barrier (BBB) is a functional and morphological interface between the systemic blood circulation and the CNS. The central regulatory component is the brain capillary endothelial cell (BEC), which is assisted by a number of cellular entities, viz. pericytes and astrocytes, together forming an interface, described as the neuro-vasculo-glial unit (NVU). The NVU has the dynamic ability to respond to the homeostatic changes in the brain interstitium ensuring a stable environment for neuronal functionality [1]. From a research point of view, it is therefore of interest to understand the capability of the BEC to withstand oxidative stress (OS), and to scrutinize the BBB in vitro models used to study these physiological processes. However, from a therapeutic point of view the strict regulatory mechanisms for molecules to cross the barrier provide a serious clinical challenge to molecules of desired therapeutic interest to reach their neural target sites [2-5].

Endothelial dysfunction-mediated vascular diseases such as BBB dysfunction have been well linked to excess production of reactive oxygen species (ROS) [6,7]. A major source of ROS in these conditions is the upregulation of nicotinamide adenine dinucleotide phosphate oxidase (Nox, especially Nox2) 
activity [8,9]. Excess superoxide $\left(\mathrm{O}_{2}^{-}\right)$produced primarily from increased Nox activity undergoes both spontaneous and enzymatic dismutation by superoxide dismutases (SOD), resulting in increase and/or accumulation of its dismutation product, hydrogen peroxide $\left(\mathrm{H}_{2} \mathrm{O}_{2}\right)$ [10]. Keeping vascular endothelial cells in redox balance involves the activities of several endogenous antioxidants whose activities may be enzymatic or non-enzymatic [10]. Superoxide dismutase (SOD) is an enzymatic, first-line, intracellular antioxidant that catalyzes the conversion of superoxide to hydrogen peroxide [11]. Other important enzymatic antioxidants such as glutathione peroxidase (GPx), and catalase (CAT), help to neutralize $\mathrm{H}_{2} \mathrm{O}_{2}$ to water and oxygen [11]

Endothelial nitric oxide synthase (eNOS) is another enzyme which normally plays a protective role in the vascular endothelial cell through its production of nitric oxide $(\mathrm{NO})$ while oxidizing its substrate L-arginine to L-citrulline using molecular oxygen $\left(\mathrm{O}_{2}\right)[12,13]$. However, parallel upregulation of eNOS and Nox as occurs in many vascular diseases results in eNOS uncoupling with subsequent conversion of eNOS to an $\mathrm{O}_{2}{ }^{-}$-producing enzyme that contributes to further vascular oxidative stress [14-16]. Furthermore, free radicals such as superoxide can attack polyunsaturated fatty acids (PUFAs) such as arachidonic acid in the cell membranes of vascular endothelial cells to yield advanced lipid peroxidation end products (ALEs) [17]. One of ALEs of relevance is 4-hydroxynonenal (4-HNE), an electrophile that is highly reactive towards nucleophilic thiols and amino groups $[17,18]$. It readily reacts with proteins (4-HNE-protein adduction), lipids, and nucleic acids of DNA. Its reaction with proteins modifies their activity thus acting as a second messenger in various biologic activities including modification of enzymatic actions or transcription factor modulations that determine cell survival or death [18]. Oxidative stress (OS) occurs in the cells when an unbalanced accumulation of ROS exists within the cell and/or in its immediate environment [19]. BBB dysfunction in relation to OS has been implicated in the initiation and propagation of several neurological conditions such as epilepsy, stroke, and degenerative neuropathies such as Alzheimer's disease, Parkinson's disease, and multiple sclerosis [20,21]. Thus, OS has been scientifically documented as a common factor to both the etiologies of these neurological disorders as well as abnormal BBB function. Cell modeling has, to date, provided a robust tool in the in vitro study of the BBB $[22,23]$. The brain microvascular endothelial cells are the principal cells of the BBB which have had several cell models characterized for use as in vitro models in the study of the BBB [24]. This study focused on two mouse-derived cell lines, b.End5 and bEnd.3, established for use as in vitro models of the BBB $[25,26]$. It is of interest to understand how the endothelial cells of the BBB respond to oxidative stress as well as the endothelial cell-specific events that underlie the abnormalities of BBB permeability. It is, however, disconcerting that most of the in vitro cell models in use for BBB studies have not been characterized for their oxidative/antioxidant features, which are necessary for the definition of OS, as well as for features that characterize changes in oxidative stress responsible for the observation of abnormal permeability under OS conditions. In this study, we profiled for the first time, b.End5 and bEnd. 3 cells, both mouse-derived cell lines obtained after immortalizing primary mouse brain endothelial cells by infection with middle $\mathrm{T}$ antigen-expressing polyoma virus, for their resistance against a suitably-selected ROS, hydrogen peroxide $\left(\mathrm{H}_{2} \mathrm{O}_{2}\right)$, which can permeate all intracellular membranes and thus exert its effects on organelles [27]. Cellular glutathione content (reduced/oxidized form [GSH/GSSG]), a well reported marker of cellular oxidative status, is a tripeptide, L- $\gamma$-glutamine-L-cysteinyl-glycine, that acts as an endogenous cellular antioxidant either by direct neutralization of ROS or as cofactor for the antioxidant enzyme, glutathione peroxidase (GPx) [28]. [Hereafter, we refer to the full component of reduced and oxidized glutathione as 'total glutathione while GSH and GSSG refer to the 'reduced glutathione' and 'glutathione disulfide/oxidized glutathione' fractions respectively]. This functional capability of GSH is conferred by its active thiol group residing in its cysteine residue [29]. Glutathione exists within cells in either the reduced (GSH) form or in oxidized form as glutathione disulfide (GSSG). It is usually synthesized as GSH but oxidized to GSSG upon participating in a redox reaction. Changes in cellular reduced glutathione content as well as changes in cell viabilities were used to assess cellular capacities to respond to varying levels of ROS. 
This protocol is robustly useful whenever it is desired to use these cells to study oxidant effects on the BBB.

\section{Materials and Methods}

\subsection{Bio-Reagents}

Analytical grade reagents were used for all experiments. These included monochlorobimane (Molecular Probe M1381MP, Eugene, OR 97402, USA), trypan blue, (Gibco 1520-061, Gaithersburg MD 20877, USA), tris (2-carboxyethyl) phosphine hydrochloride, TCEP (Sigma C4706, Laramie, WY 82070, USA), GSH-Glo ${ }^{\text {TM }}$ Glutathione Assay Kit (Promega V6911/2, Madison, WI 53711, USA), Trolox (( \pm )-6-Hydroxy-2,5,7,8-tetramethylchromane-2-carboxylic acid, Sigma 238813, Laramie, WY 82070, USA), Cell Proliferation Kit II (XTT) (Roche, Sigma 11465015001, Laramie, WY 82070, USA), and hydrogen peroxide (30\%, Merck Millipore 107209, Feldbergstraße 80, 64293 Darmstadt, Germany).

\subsection{Cell Cultures}

Two mouse brain endothelioma cell lines (b.End5 and bEnd.3) were used in this study. The b.End5 (ECACC 96091930, Salisbury, Wiltshire SP4 0JG, UK) cells were cultured in Dulbecco's modified Eagle's medium (DMEM Lonza BE 12-719F, Salisbury, MD 21801, USA.) supplemented with 10\% fetal bovine serum (FBS Biowest12010S181G, Rue du Vieux Bourg, 49340 Nuaillé, France), 100 U/mL penicillin/streptomycin (Lonza DE17-602E), $1 \mathrm{mM}$ sodium pyruvate solution (Lonza BE13-115E), and $1 \%$ non-essential amino acids (NEAA Lonza BE13-114E) at $37{ }^{\circ} \mathrm{C}$ and $5 \% \mathrm{CO}_{2}$ in a humidified incubator. For all experiments, b.End5 cells at passages 5-20 were used and culture medium was changed every 2-3 days. Prior to experimentation, cells were rinsed in $1 \times$ phosphate buffer solution (PBS). The adherent cells were detached by the addition of $0.25 \%$ trypsin-EDTA after which equal volume of fresh media was added and the cell suspension aspirated into $15 \mathrm{~mL}$ conical tubes. The cell suspensions were then centrifuged for $5 \mathrm{~min}$ at rpm of 2500 to obtain a cell pellet. The supernatant was then removed by gentle aspiration and thereafter, $5 \mathrm{~mL}$ of fresh media added to bring the cell pellets back in suspension. The bEnd.3 (ATCC ${ }^{\circledR}$ CRL-2299, Gaithersburg, MD 20877, United States ) cells were cultured in Dubelcco's Eagle's medium (Gibco 11320074) supplemented with $10 \%$ fetal bovine serum (FBS Biowest S12010S181G), $100 \mathrm{U} / \mathrm{mL}$ penicillin/streptomycin (Lonza DE17-602E), and L-glutamine to a final concentration of $4.1 \mathrm{mM}$ (Invitrogen 25030081, Camarillo, CA 93012, United States ) and at $37^{\circ} \mathrm{C}$ and $5 \% \mathrm{CO}_{2}$ in a humidified incubator. The bEnd.3 cells used for all experiments were at passages 5-20 and the medium was changed every 2-3 days. Prior to cell seeding for experiments, adherent bEnd. 3 cells were similarly brought to suspension as described for the b.End5 cells.

\subsection{Hydrogen Peroxide Treatments}

A stock solution of $\mathrm{H}_{2} \mathrm{O}_{2}$ (9.8 M, Merck Millipore, Feldbergstraße 80, 64293 Darmstadt, Germany) was diluted to the required concentrations in complete media. Cultured b.End5 and bEnd. 3 cells were divided into labelled treatment wells exposed to $\mathrm{H}_{2} \mathrm{O}_{2}$ concentrations ranging between $10 \mu \mathrm{M}$ and $2 \mathrm{mM}$ and cells that were unexposed to $\mathrm{H}_{2} \mathrm{O}_{2}$ served as control. To determine the antioxidant capacity of cultured cells both b.End5 and bEnd. 3 cells were seeded in separate transparent 96-well plates at $1 \times 10^{4}$ cells per well in $200 \mu \mathrm{L}$ of normal media and allowed to attach overnight. Media were then aspirated and replaced with either $100 \mu \mathrm{L}$ of fresh media to serve as control or $100 \mu \mathrm{L}$ of media dosed with the appropriate concentrations of hydrogen peroxide for another $24 \mathrm{~h}$. Experiments were repeated thrice and average values of parameters were recorded. Viability of the cells exposed to different concentrations of hydrogen peroxide were then analysed and compared against viability measures for the control cells under same duration in culture. 


\subsection{Viability Assay}

Cells were cultured in a transparent 96-well plate as described for hydrogen peroxide treatments. Equal numbers of $b$.End5 cells were seeded into eighteen treatment $\left(\mathrm{H}_{2} \mathrm{O}_{2}\right)$ wells $(n=3)$ starting from control (unexposed) and treatment with $\left[\mathrm{H}_{2} \mathrm{O}_{2}\right]$ in multiples of $50 \mu \mathrm{M}$ up to a maximum of $850 \mu \mathrm{M}$. For cultured bEnd. 3 cells, equal numbers of cells were seeded into sixteen sets of 3 wells $(n=3)$ and treated as control (unexposed), then $\left[\mathrm{H}_{2} \mathrm{O}_{2}\right]$ in multiples of $10 \mu \mathrm{M}$ up to $100 \mu \mathrm{M}$ and then in multiples of $100 \mu \mathrm{M}$ up to a maximum of $500 \mu \mathrm{M}$. A blank column of three wells was also included in both treatment plates to facilitate the determination of relative absorbance units. The XTT [30] viability assay kit (Roche) was used to quantify cell viability after treatment for $24 \mathrm{~h}$. The XTT reagent was reconstituted by mixing $100 \mu \mathrm{L}$ of electron-coupling reagent $(0.383 \mathrm{mg} / \mathrm{mL})$ with $5 \mathrm{~mL}$ of XTT labelling reagent $(1 \mathrm{mg} / \mathrm{mL})$ to activate it as per manufacturer's recommendation. Reconstituted XTT, $50 \mu \mathrm{L}$, was then added to each well containing $100 \mu \mathrm{L}$ of cell culture and incubated for $4 \mathrm{~h}$ at $37^{\circ} \mathrm{C}$ in a $\mathrm{CO}_{2}$ incubator. Absorbance was then read for each well at $450 \mathrm{~nm}$ and blank-corrected values obtained using a GloMax-Multi Detection System (Promega, Madison, WI 53711, USA). The absorbance measures directly correlated with the viability of the cells in each well.

\subsection{Fluorescent Detection of Glutathione in Cultured Cells}

Equal numbers of b.End 5 and bEnd. 3 cells were cultured under standard conditions on microscopic glass slides in separate Petri dishes. The cells were then allowed to attach overnight in all Petri dishes and cells on each slide were used to demonstrate glutathione. Briefly, the medium was removed from the attached cells and were rinsed twice with PBS solution, $\mathrm{pH}, 7.4$, and then incubated with monochlorobimane solution (mBCl, Molecular Probe $\left.{ }^{\mathrm{TM}} \mathrm{M} 1381 \mathrm{MP}\right) 60 \mu \mathrm{M}$ in complete DMEM for $30 \mathrm{~min}$ [31]. Following $\mathrm{mBCl}$ loading, slides were fixed using a mixture of $4 \%$ paraformaldehyde (PFA) and $0.2 \%$ glutaraldehyde (GA) in PBS solution at $\mathrm{pH} 7.4$ for $10 \mathrm{~min}$ and following fixation, cells were nuclear-counterstained by incubating slides with $20 \mu \mathrm{g} / \mathrm{mL}$ propidium iodide (PI) solution for $15 \mathrm{~min}$. DABCO (1,4-diazobicyclo-[2,2,2]-octane) mountant, $20 \mu \mathrm{L}$, was added to each slide mounted with cover slips. Cells on each slide were then viewed and imaged under a Nikon Eclipse 50i fluorescent microscope at $\lambda_{\mathrm{ex}} / \lambda_{\mathrm{em}}$ of $365 / 490 \mathrm{~nm}$ and $439 / 636 \mathrm{~nm}$ for $\mathrm{mBCl}$ and PI, respectively.

\subsection{Quantification of Total Cellular Glutathione in bEnd5 Cells}

To accurately quantify the total amount of glutathione in a single b.End5/bEnd.3 cell, we used a GSH-Glo ${ }^{\mathrm{TM}}$ Glutathione Assay Kit which works by a luminescence assay to detect and quantify glutathione [32]. The assay is based on the conversion of a luciferin derivative into luciferin in the presence of glutathione, catalyzed by glutathione-S-transferase (GST). The reaction is further coupled with a firefly luciferase which leads to the generation of luminescence signal proportional to the amount of glutathione in the sample. To estimate glutathione fairly accurately in $1 \times 10^{4}$ cells, according to manufacturer's recommendation and to control for cell proliferation occurring alongside cell attachment, cells were plated in white 96 -well plates and incubated at $37{ }^{\circ} \mathrm{C}$ and $5 \% \mathrm{CO}_{2}$ at a density of $4 \times 10^{3}$ cells per well for the b.End5 cells and $4.5 \times 10^{3}$ cells per well for the bEnd.3 cells, based on an optimized number of the respective cells that gave the target density at $24 \mathrm{~h}$ in culture (based on our data from proliferation study, not shown). Cells were plated in columns of four wells $(n=4)$ in a 96-well white bottom plate and $100 \mu \mathrm{L}$ of prepared $1 \mathrm{X}$ GSH-Glo reagent was transferred to each well. In order to measure the total glutathione (GSH + GSSG), $100 \mu \mathrm{L}$ of $1 \mathrm{mM}$ tris (2-carboxyethyl) phosphine (TCEP) was added to a group of four wells in addition to the GSH-Glo reagent according to the GSSG recycling method [33]. The contents of the wells were agitated briefly on an orbital shaker before incubation at room temperature for $30 \mathrm{~min}$. Then, $100 \mu \mathrm{L}$ of reconstituted luciferin detection reagent was transferred to each well, and the plate was mixed briefly on an orbital shaker before incubation at room temperature for $15 \mathrm{~min}$. Luminescence values were then read using a GloMax-Multi Detection System (Promega, Madison, WI 53711, USA). Luminescence readings were 
converted to GSH concentration using a standard curve generated from a $5 \mathrm{mM}$ GSH standard supplied by the manufacturer.

\subsection{Statistical Analysis}

Statistical analysis was done using Graph Pad Prism.5 statistical analysis software. Data were expressed as mean \pm SEM and significant differences in data were accepted at $p<0.05$

\section{Results}

In this study differences in antioxidant capacities of two brain endothelial cell lines from the same animal species were observed. We firstly established baseline data for both cell lines in terms of their endogenous glutathione concentrations, and secondly, we profiled the response of these cell lines to an exogenous ROS stress, $\mathrm{H}_{2} \mathrm{O}_{2}$, with respect to the content of the endogenous antioxidant, glutathione, using fluorescent imaging, and fluoro-spectrometric quantification.

\subsection{Both b.End5 and bEnd.3 Cells Demonstrated Glutathione Presence on Fluorescent Microscopy}

We first investigated presence and distribution of glutathione in each of the selected cell lines. Monochlorobimane with propidium iodide nuclear counterstaining revealed blue fluorescence due to the presence of glutathione while the nuclei fluoresced red (Figure 1). Both cells appeared intensely fluorescent for glutathione, however, bEnd.3 showed less cytoplasmic glutathione possibly due to a higher nucleo-cytoplasmic ratio. Variable segments and rings of blue fluorescence were observed around the periphery of the nuclei in both cells (Figure 1, Plates A2 and B2) which are evidence of glutathione presence within the nuclear structure. This was more prominently observed at the nucleo-cytoplasmic interface in both cell types and especially in the bEnd.3 cell (Figure 1, Plate B2).
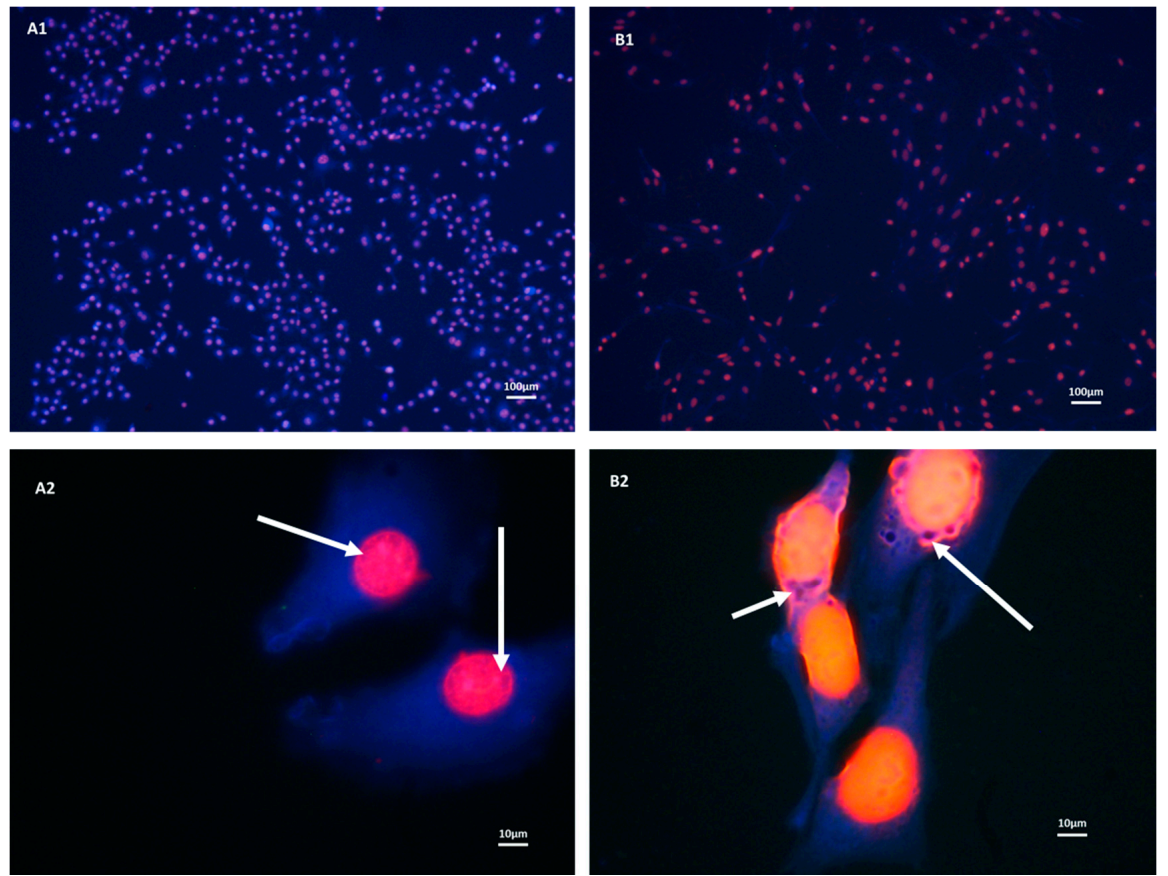

Figure 1. Micrographs show fluorescent images of b.End5 (A1) and (A2) and bEnd.3 cells (B1) and (B2) in normal culture. Both cells showed blue monochlorobimane solution $(\mathrm{mBCl})$ fluorescence (due to binding with reduced glutathione (GSH)) in their cytoplasm, though at the higher magnification b.End5 appeared more deeply stained. Furthermore, plate A2 revealed a lower nucleo-cytoplasmic ratio in b.End5 cells suggesting more cytoplasmic GSH content than in bEnd. 3 cells. Furthermore, multiple segments and rings of blue fluorescence (white arrows) were indicative of glutathione observed within the nuclei and nucleo-cytoplasmic interface in the cells of both cell types (Plates A2 and B2). 


\subsection{Glutathione Contents of Both b.End5 and bEnd.3 Cells Are Comparable in Normal Culture}

The difference in blue fluorescence between the two cell types provided micrographical evidence for the presence and distribution of glutathione. The objective quantification of the levels of glutathione in each cell type was required to compare the cells' ability to respond to OS (Figure 2).

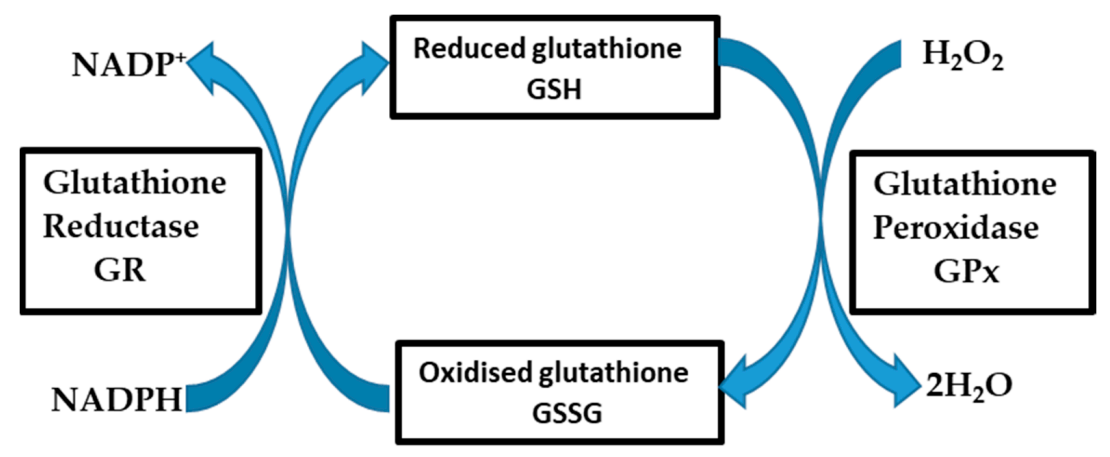

Figure 2. The above diagram illustrates the redox buffering reaction of the glutathione system. Glutathione peroxidase (GPx) enzymatically converts $\mathrm{H}_{2} \mathrm{O}_{2}$ to $2 \mathrm{H}_{2} \mathrm{O}$ using reduced glutathione (GSH) as substrate which is then converted to its oxidized form, glutathione disulfide (GSSG) in the process. The GSSG in a second reaction involving glutathione reductase enzyme is converted back to GSH and thus GSH is recycled. The glutathione reductase reaction contributes significantly to the cellular maintenance of pooled reduced glutathione for redox defense.

Total and reduced fraction of the glutathione content in both cell types were experimentally determined while the content of oxidized glutathione was derived by deduction of the reduced glutathione values from the respective total glutathione values. The value of the total glutathione was obtained by reducing the GSSG fraction in each sample using TCEP which also has the ability to recover protein-bound GSH. However, because GSH exists within cells either freely or bound to proteins the recovered GSH still constituted a fraction of the total glutathione pool. In b.End 5 cells the amount of glutathione per unit cell was higher than that of bEnd.3, however, the difference was not statistically significant $(p=0.1325$ ) (Figure 3). Estimated values were $2.769 \pm 0.113 \mathrm{fM} / \mathrm{cell}$ for b.End5 and $2.305 \pm 0.219 \mathrm{fMol} / \mathrm{cell}$ for bEnd.3. Corresponding GSSG values for both $b$.End 5 and $b$ End. 3 cells were respectively $0.139 \pm 0.006 \mathrm{fM} /$ cell and $0.115 \pm 0.011 \mathrm{fM} /$ cell. GSH/GSSG ratio in both cells approximated to $95 \% / 5 \%$.

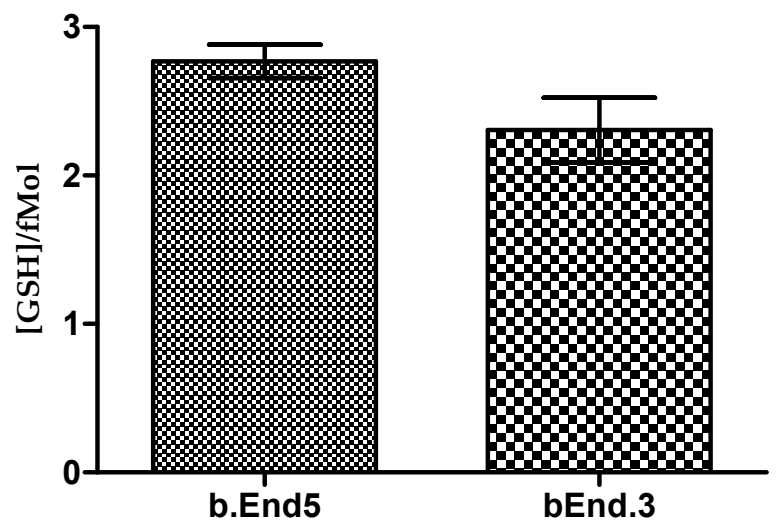

Figure 3. A comparison of GSH concentration in the two types of cells revealed no statistical difference between the two means (Student's $t$ test: $p=0.1325$ ).

\subsection{Antioxidant Capacity Is Higher in b.End5 Cells}

Although both cell lines tested showed that glutathione was abundantly present in both the cytoplasm and nucleoplasm, the response of these cell lines to ROS stress remains to be investigated. 
Both bEnd. 3 and b.End5 cells treated with increasing concentrations of hydrogen peroxide showed changes in viability which correlated with the relative absorbance units obtained from XTT proliferation assay. The assay is based on the cleavage of the yellow tetrazolium salt, XTT, to form an orange formazan dye by mitochondrial dehydrogenases in metabolically active cells. Because an increase in the number of cells results in an increase in the overall activity of mitochondrial dehydrogenases in the samples, these changes correlated to the amount of orange formazan formed, a parameter that was monitored by the relative changes in the absorbance. The viability changes in both cells were normalized as percentages of the control, unexposed, cells and plotted against the logarithmic values of the various concentrations and the half-maximal inhibitory concentrations $\left(\mathrm{IC}_{50}\right)$ were determined and compared for the two cells (Figure 4A,B). Experiments were repeated three times and average values were analyzed. Results showed that the $\mathrm{IC}_{50}$ for the b.End5 cell was significantly higher than for the bEnd.3 cell (Figure 4C).

A. $\log \left[\mathrm{H}_{2} \mathrm{O}_{2}\right]$ against viability $(\%)$ for b.End5

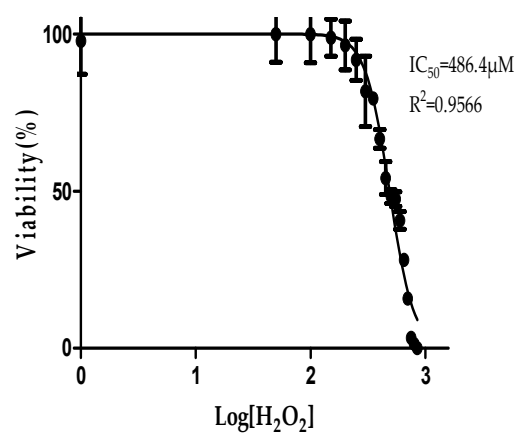

C. IC $_{50}$ values compared for b. End5 and bEnd.3

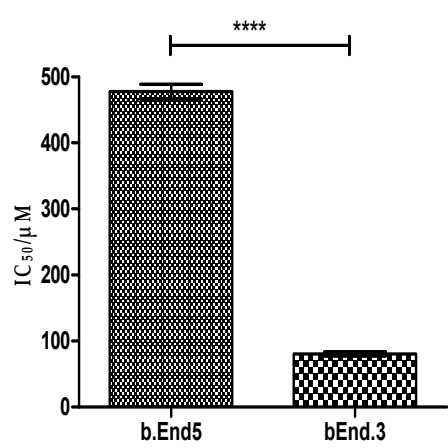

B. Log $\left[\mathrm{H}_{2} \mathrm{O}_{2}\right]$ against viability (\%) for bEnd.3

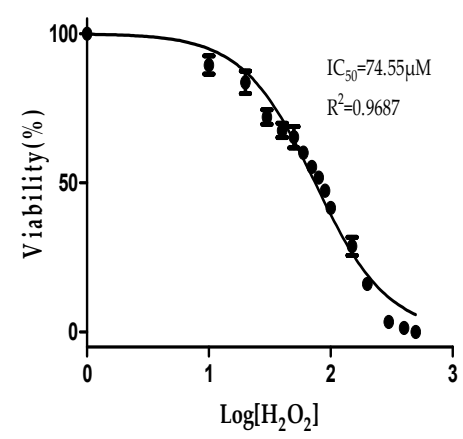

Figure 4. A non-linear regression analysis of logarithmic values of $\left[\mathrm{H}_{2} \mathrm{O}_{2}\right]$ against normalized viability was used to determine the hydrogen peroxide concentration that caused $50 \%$ inhibition of cell viability in b.End5 cells. Cells were exposed to $\left[\mathrm{H}_{2} \mathrm{O}_{2}\right]$ that ranged between 0 (control) and $850 \mu \mathrm{M}$ for $24 \mathrm{~h}$ in flat-bottom transparent 96-well plates. Viability changes correlated to the absorbance measured at $450 \mathrm{~nm}$ from each well following incubation with XTT reagent for $4 \mathrm{~h}$. (A) Results showed $\mathrm{IC}_{50}$ for b.End5 cell as equivalent of $486.4 \mu \mathrm{M}$ at $\mathrm{r}^{2}=0.9566$. (B) Data for bEnd.3 cells was obtained by exposing cultured bEnd. 3 cells to $\left[\mathrm{H}_{2} \mathrm{O}_{2}\right]$ ranged from 0 (control) to $500 \mu \mathrm{M}$ and non-linear regression analysis done as described above. Results showed $\mathrm{IC}_{50}$ for bEnd.3 cell to be $74.55 \mu \mathrm{M}$ at r ${ }^{2}=0.9687 \mu \mathrm{M}$. (C) Graph of the $\mathrm{IC}_{50}$ values for the b.End5 compared with the same values for the bEnd.3 cells (annotation * denotes statistically significant difference between the values shown). $\mathrm{IC}_{50}$ values for b.End5 and bEnd. 3 cells were statistically compared using the Student's $t$ test. The analyzed data showed that the $\mathrm{IC}_{50}$ value was significantly higher for b.End5 cell than for the bEnd.3 cell $(p<0.0001)$. 


\subsection{Glutathione Was More Resistant to Oxidant Depletion in b.End5}

Changes in the glutathione content of equal number of cells were plotted against the hydrogen peroxide concentrations. This allowed for the analysis of the physiological response (endogenous antioxidant response) of the two cell lines to increased $\mathrm{H}_{2} \mathrm{O}_{2}$ concentrations. The profile in glutathione depletion against increasing concentrations of hydrogen peroxide for the two cell lines was examined (Figure 5A,B). The data showed a steady decline in the glutathione content of the bEnd.3 cells (Figure 5B) while the b.End5 cells, in contrast, showed an initial significant increase in glutathione content and then a decline (Figure 5A). In b.End5 cells, glutathione increase was sustained either higher or at par with the control cells until about a concentration of $500 \mu \mathrm{M}$ which was close to its IC $_{50}$ value (Figure 5A). Also, the glutathione content of $b$.End5 cells were observed to decline to a steady lowest value at about $1 \mathrm{mM}$ hydrogen peroxide concentration and thereafter remained constant.

A

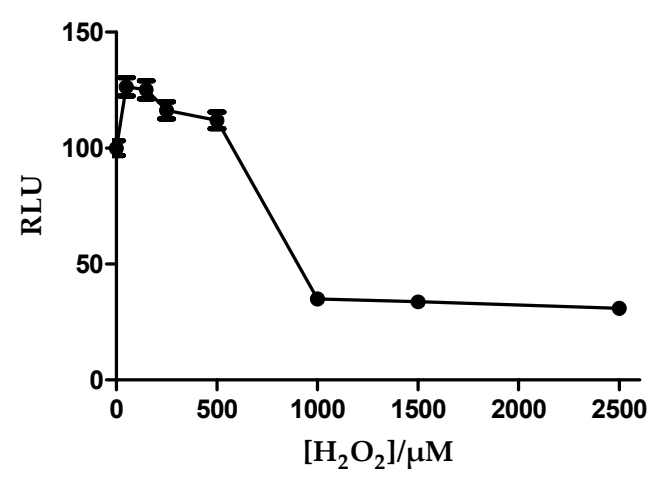

B

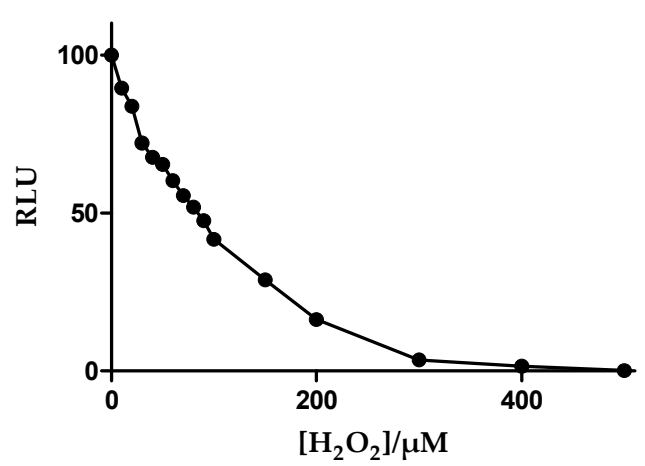

Figure 5. (A) and (B) show trends in the glutathione contents of b.End5 and bEnd 3 cells with exposure to increasing $\left[\mathrm{H}_{2} \mathrm{O}_{2}\right]$. Cells were exposed to increasing concentrations of $\left[\mathrm{H}_{2} \mathrm{O}_{2}\right]$ for $24 \mathrm{~h}$ and average cellular glutathione contents estimated using the GSH-Glo kit. Glutathione contents of the cells correlated directly to the relative luminescent values (RLU) obtained following incubation with the optimized reagents of the GSH-Glo assay kit described. Data in Figure 4A represents b.End5 cells and shows an upward trend in the glutathione content of the b.End5 cells upon exposure to $\left[\mathrm{H}_{2} \mathrm{O}_{2}\right]$ of 0-250 $\mu \mathrm{M}$. Above this concentration was observed a downward trend though values remained higher or at par with the starting point until $\left[\mathrm{H}_{2} \mathrm{O}_{2}\right]$ higher than $500 \mu \mathrm{M}$. From this point a steady decline occurred until about $1 \mathrm{mM}\left[\mathrm{H}_{2} \mathrm{O}_{2}\right]$ followed by a plateau but not a complete depletion. Data in Figure $4 \mathrm{~B}$ represent the trend in bEnd.3 glutathione changes with increasing $\left[\mathrm{H}_{2} \mathrm{O}_{2}\right]$. A steady decline was observed until complete depletion at about $400 \mu \mathrm{M}\left[\mathrm{H}_{2} \mathrm{O}_{2}\right]$.

\section{Discussion}

Although several previous reports have reported the existence of strain-specific genes in contributing to some differences in the physiological characteristics of different organs and/or systems in animals of the same species [34-36], researchers have largely ignored this evidence in choosing cell lines to model a physiological system. This is particularly evident in the use of cell lines modelling the BBB, where a variety of primary and immortalized cell lines have been used to study its physiological functions. This phenomenon creates un-necessary murkiness in comparing data between different studies. In this study, we were able to illustrate convincingly that differences in the antioxidant characteristics of the two cell lines (b.End5 and bEnd.3) (Figure 4A-C) of the same species, have distinctly different response profiles to an escalating ROS stressor. These two cells were derived from primary brain endothelial cells of two different mouse strains, BALB/c and SV129 respectively, by infection with a retrovirus coding for the Polyoma middle T-antigen [37,38]. Both have been used extensively to study BBB function [39-41], all with the underlying assumption, that there is physiological parity between these cell lines. 
We investigated the cellular content of the glutathione antioxidant in the two cell types under normal culture conditions (as per the instructions provided by the suppliers), first by fluorescent microscopy, and although we easily established the cellular presence for glutathione, we were unable to distinguish clear quantitative differences between the two cell lines. Close examination of the fluorescence micrographs clearly illustrated the even distribution of glutathione throughout the cytoplasm of both cell types, however, the higher ring of fluorescence just inside the nuclear membrane seem to suggest that glutathione plays an important role in neutralizing ROS entering into the nucleus. Given that DNA fragmentation is prone under conditions of OS [42,43], this provides solid circumstantial evidence as to the role of glutathione in protecting the nuclear material from ROS compromise. Although fluorescence demonstrated the presence of glutathione in both types of cells, the presence of blue fluorescence provided subjective evidence of increased cytoplasmic glutathione within b.End5 cells as evidenced by a lower nucleo-cytoplasmic ratio in the b.End5 cells with consequently more cytoplasmic content of glutathione.

Our quantitative data of the glutathione content of the b.End5 and bEnd.3 cell types substantiated our visual observations and, although b.End5 cells had a slightly higher mean glutathione content, statistically no significant difference in glutathione quantity was found between the respective cell lines (Figure 3). Calculations from data indicated that the GSH concentration per unit cell for the b.End5 and bEnd. 3 cell types were within the range of $2.769 \pm 0.113 \mathrm{fMol}$ and $2.305 \pm 0.219 \mathrm{fMol}$ respectively. Both cell types also have GSH/GSSG ratio of approximately $95 \% / 5 \%$ which indicated that both cells were redox-stable in normal culture. Comparisons of the average cellular glutathione per single cell for both the b.End 5 and bEnd. 3 cell lines predict that these cells are well suited for OS resistance in that their GSH contents are in the range of cells specialized for detoxification, such as the liver cancer cell line, HepG2 with GSH content of $2.9 \mathrm{fMol} / \mathrm{cell}$ [44]. These data, taken independently endorses the use of these cell lines for BBB modeling. It is presumptuous to assume that simply on the basis that the cell lines have similar basal levels of endogenous antioxidants that these cells may indeed respond to incremental ROS stress in a similar manner. This is all the more complicated given the arbitrary concentrations of ROS stressors used in experiments to demonstrate OS on the BBB [45,46].

To evaluate the response of the endogenous antioxidant glutathione to incremental concentrations of $\mathrm{H}_{2} \mathrm{O}_{2}$ in each cell-line, we then determined the relative levels of $\mathrm{OS}$ that causes decompensation of the GSH/GSSG antioxidant system in the cell after $24 \mathrm{~h}$ exposure (Figure $4 \mathrm{~A}, \mathrm{~B}$ ). In this study we profiled the cell lines using the glutathione system which has been reported as a reliable and sensitive marker of oxidative cellular status $[47,48]$. Furthermore, because the physiological variable of cell viability was used as a general indicator of the response of the cells to $\operatorname{ROS}\left(\mathrm{H}_{2} \mathrm{O}_{2}\right)$, it is scientifically plausible that viability changes will be a reliable indicator of the total cellular antioxidant capacity, and therefore, a singular marker (glutathione) would provide enough insight on the differences in the total antioxidant capacities of the two cell lines. Using the $\mathrm{IC}_{50}$ [49]values for comparison, we documented for the first time evidence of a significantly greater capability of the b.End5 cells to neutralize higher ROS concentrations than the bEnd.3 cells ( $p<0.0001]$ Figure 4 C). When we studied the profile in the GSH depletion within the cells exposed to increasing ROS load the data showed that the bEnd 3 cell type has a very limited ability for de novo upregulation of glutathione synthesis under condition of increased ROS accumulation (Figure 5B), whereas the b.End5 cell type showed ability to sustain adequate levels of glutathione, to elevate levels of GSH in response to initial low concentration of ROS, and to maintain this sustained endogenous GSH levels despite several subsequent increases in the concentration of ROS (Figure 5A). The mechanism for this divergent reaction of the glutathione system in the two cell types against increasing concentration of ROS is not clear, and requires further study. However, this observed difference is suggestive of inter-strain differences in the system that regulates ROS accumulation within these cells, as has been reported for several diverse physiological characteristics in different strains of cells from the same species of animal $[35,49,50]$. Differentially expressed genes in specific domains of the system that regulate ROS in intracellular milieu or perhaps strain-specific genetic alteration following viral oncogenic transformation of the primary cells could be responsible [51]. 
Mouse strain-specific differences in neuro-behavior, neuronal excitability, susceptibility to fibrosis, anti-inflammatory response, and bone density have been previously reported [50]. These previous reports have strengthened our position that strain-specific genes are very important in shaping the phenotypic differences in the two cell types investigated with respect to their glutathione system plasticity to OS. This finding has an important bearing on experimental designs aimed at studying effects of OS on the BBB. However, whether these two mouse cells respond differently to OS in the in vivo situation is not known. We propose here that a genome-wide genetic screen of the cells in use for evaluating the physiology of the BBB will identify important differences in the genes that control several key functions of the BBB [52]. Also, further research is required to determine these properties in primary cells of the mouse brain endothelial cells with the potential for the unraveling of the true behavior of the mouse brain endothelial cells during OS conditions with respect to capacity for ROS neutralization and the glutathione system response.

Given that under control conditions we are confident that the BECs would be in redox balance, it is, therefore, unimportant to localize the source of endogenous ROS production in response to exogenous ROS exposure, neither does it make scientific sense to measure ROS production from the cell organelles when the source of ROS was clearly defined as the experimental treatment (exogenous $\mathrm{H}_{2} \mathrm{O}_{2}$ ). Exogenous ROS treatment would gauge the physiological capacity of the cells to respond to ROS exposure from an exogenous source. Exogenous exposure would be additional to the normal ROS load generated by normal physiological cellular processes. Thus, the measuring of ROS levels while exposing cells to exogenous $\mathrm{H}_{2} \mathrm{O}_{2}$ in this study would be superfluous. Nevertheless, it might be assumed that the study largely ignored the spatiotemporal localization and quantification of endogenous ROS production, but we are aware of the lack of the use of these techniques, which is intended to be the focus of our future study, in which we propose to measure ROS produced endogenously by cellular organelles using a combination of immuno-electron microscopy as qualitative and ELISA as semi-quantitative methods [53-55].

\section{Conclusions}

The glutathione system responses and ROS buffering capacities are clearly linked and they determine the magnitude of ROS that induces OS in the b.End5 and bEnd.3 mouse brain endothelial cell line models of the BBB. Strain-specific differences in the different cells will result in different definitions of OS in different models of different animal strains within the same species. Thus it is important to establish experimental parameters that best define OS for each endothelial cell model of the BBB for reproducibility. Such information will avail researchers of opportunity to verify and select appropriate models of BBB endothelial cells for specific redox investigations and enable them to draw comparable and reproducible conclusions.

Author Contributions: O.A.: conceptualization, investigation, methodology, formal analysis, and writing-original draft. M.R.: investigation assistance. O.E.: resources, writing-review, and editing. D.F.: resources, supervision, writing - review, and editing. All authors have read and agreed to the published version of the manuscript.

Funding: This research was funded by Tertiary Education Trust Fund (AST\&D/LAUTECH/2014) and UWC-SNS Funding.

Acknowledgments: The authors wish to acknowledge the technical support of Shireen Mentor.

Conflicts of Interest: The authors declare no conflict of interest.

\section{References}

1. Abbott, N.J.; Patabendige, A.A.; Dolman, D.E.; Yusof, S.R.; Begley, D.J. Structure and function of the blood-brain barrier. Neurobiol. Dis. 2010, 37, 13-25. [CrossRef] [PubMed]

2. Ramirez, S.H.; Potula, R.; Fan, S.; Eidem, T.; Papugani, A.; Reichenbach, N.; Dykstra, H.; Weksler, B.B.; Romero, I.A.; Couraud, P.O.; et al. Methamphetamine disrupts blood brain barrier function by induction of oxidative stress in brain endothelial cells. J. Cereb. Blood Flow Metab. 2009, 29, 1933-1945. [CrossRef] [PubMed] 
3. Betzer, O.; Shilo, M.; Motiei, M.; Popovtzer, R. Insulin-coated gold nanoparticles as an effective approach for bypassing the blood-brain barrier. Nanoscale Imaging Sens. Actuation Biomed. Appl. XVI 2019, 10891, $108911 \mathrm{H}$.

4. Zhao, Z.; Nelson, A.R.; Betsholtz, C.; Zlokovic, B.V. Establishment and dysfunction of the blood-brain barrier. Cell 2015, 163, 1064-1078. [CrossRef]

5. Zhao, Z.; Sagare, A.P.; Ma, Q.; Halliday, M.R.; Kong, P.; Kisler, K.; Winkler, E.A.; Ramanathan, A.; Kanekiyo, T.; $\mathrm{Bu}, \mathrm{G}$. Central role for PICALM in amyloid- $\beta$ blood-brain barrier transcytosis and clearance. Nat. Neurosci. 2015, 18, 978-987. [CrossRef]

6. Liebner, S.; Dijkhuizen, R.M.; Reiss, Y.; Plate, K.H.; Agalliu, D.; Constantin, G. Functional morphology of the blood-brain barrier in health and disease. Acta Neuropathol. 2018, 135, 311-336. [CrossRef]

7. Nation, D.A.; Sweeney, M.D.; Montagne, A.; Sagare, A.P.; D'Orazio, L.M.; Pachicano, M.; Sepehrband, F.; Nelson, A.R.; Buennagel, D.P.; Harrington, M.G. Blood-brain barrier breakdown is an early biomarker of human cognitive dysfunction. Nat. Med. 2019, 25, 270-276. [CrossRef]

8. Fan, L.M.; Cahill-Smith, S.; Geng, L.; Du, J.; Brooks, G.; Li, J.-M. Aging-associated metabolic disorder induces Nox2 activation and oxidative damage of endothelial function. Free Radic. Biol. Med. 2017, 108, 940-951. [CrossRef] [PubMed]

9. Breitenbach, M.; Rinnerthaler, M.; Weber, M.; Breitenbach-Koller, H.; Karl, T.; Cullen, P.; Basu, S.; Haskova, D.; Hasek, J. The defense and signaling role of NADPH oxidases in eukaryotic cells. Wien. Med. Wochenschr. 2018, 168, 286-299. [CrossRef]

10. Sies, H.; Berndt, C.; Jones, D.P. Oxidative Stress. Annu. Rev. Biochem. 2017, 86, 715-748. [CrossRef]

11. Mirończuk-Chodakowska, I.; Witkowska, A.M.; Zujko, M.E. Endogenous non-enzymatic antioxidants in the human body. Adv. Med. Sci. 2018, 63, 68-78. [CrossRef] [PubMed]

12. Forstermann, U.; Munzel, T. Endothelial nitric oxide synthase in vascular disease: From marvel to menace. Circulation 2006, 113, 1708-1714. [CrossRef] [PubMed]

13. Koch, S.R.; Choi, H.; Mace, E.H.; Stark, R.J. Toll-like receptor 3-mediated inflammation by p38 is enhanced by endothelial nitric oxide synthase knockdown. Cell Commun. Signal. 2019, 17, 33. [CrossRef] [PubMed]

14. Santhanam, A.V.R.; d'Uscio, L.V.; He, T.; Das, P.; Younkin, S.G.; Katusic, Z.S. Uncoupling of endothelial nitric oxide synthase in cerebral vasculature of Tg2576 mice. J. Neurochem. 2015, 134, 1129-1138. [CrossRef]

15. Drummond, G.R.; Cai, H.; Davis, M.E.; Ramasamy, S.; Harrison, D.G. Transcriptional and posttranscriptional regulation of endothelial nitric oxide synthase expression by hydrogen peroxide. Circ. Res. 2000, 86, 347-354. [CrossRef]

16. Toda, N.; Okamura, T. Cigarette smoking impairs nitric oxide-mediated cerebral blood flow increase: Implications for Alzheimer's disease. J. Pharmacol. Sci. 2016, 131, 223-232. [CrossRef]

17. Enciu, A.-M.; Gherghiceanu, M.; Popescu, B.O. Triggers and Effectors of Oxidative Stress at Blood-Brain Barrier Level: Relevance for Brain Ageing and Neurodegeneration. Oxidative Med. Cell. Longev. 2013, 2013, 1-12. [CrossRef]

18. Dalleau, S.; Baradat, M.; Gueraud, F.; Huc, L. Cell death and diseases related to oxidative stress: 4-hydroxynonenal (HNE) in the balance. Cell Death Differ. 2013, 20, 1615-1630. [CrossRef]

19. Sies, H. On the history of oxidative stress: Concept and some aspects of current development. Curr. Opin. Toxicol. 2018, 7, 122-126. [CrossRef]

20. Dohgu, S.; Takata, F.; Matsumoto, J.; Kimura, I.; Yamauchi, A.; Kataoka, Y. Monomeric $\alpha$-synuclein induces blood-brain barrier dysfunction through activated brain pericytes releasing inflammatory mediators in vitro. Microvasc. Res. 2019, 124, 61-66. [CrossRef]

21. Solé, M.; Esteban-Lopez, M.; Taltavull, B.; Fábregas, C.; Fadó, R.; Casals, N.; Rodríguez-Álvarez, J.; Miñano-Molina, A.J.; Unzeta, M. Blood-brain barrier dysfunction underlying Alzheimer's disease is induced by an SSAO/VAP-1-dependent cerebrovascular activation with enhanced A $\beta$ deposition. Biochim. Et Biophys. Acta (BBA)-Mol. Basis Dis. 2019, 1865, 2189-2202.

22. Gastfriend, B.D.; Palecek, S.P.; Shusta, E.V. Modeling the blood-brain barrier: Beyond the endothelial cells. Curr. Opin. Biomed. Eng. 2018, 5, 6-12. [CrossRef] [PubMed]

23. Campisi, M.; Shin, Y.; Osaki, T.; Hajal, C.; Chiono, V.; Kamm, R.D. 3D self-organized microvascular model of the human blood-brain barrier with endothelial cells, pericytes and astrocytes. Biomaterials 2018, 180, 117-129. [CrossRef] [PubMed] 
24. Linville, R.M.; DeStefano, J.G.; Sklar, M.B.; Xu, Z.; Farrell, A.M.; Bogorad, M.I.; Chu, C.; Walczak, P.; Cheng, L.; Mahairaki, V. Human iPSC-derived blood-brain barrier microvessels: Validation of barrier function and endothelial cell behavior. Biomaterials 2019, 190, 24-37. [CrossRef]

25. Steiner, O.; Coisne, C.; Engelhardt, B.; Lyck, R. Comparison of immortalized bEnd5 and primary mouse brain microvascular endothelial cells as in vitro blood-brain barrier models for the study of $\mathrm{T}$ cell extravasation. J. Cereb. Blood Flow Metab. 2011, 31, 315-327. [CrossRef]

26. He, F.; Yin, F.; Peng, J.; Li, K.Z.; Wu, L.W.; Deng, X.L. Immortalized mouse brain endothelial cell line Bend.3 displays the comparative barrier characteristics as the primary brain microvascular endothelial cells. Zhongguo Dang Dai Er Ke Za Zhi = Chin. J. Contemp. Pediatrics 2010, 12, 474-478.

27. Glasauer, A.; Chandel, N.S. Ros. Curr. Biol. 2013, 23, R100-R102. [CrossRef]

28. Lushchak, V.I. Glutathione Homeostasis and Functions: Potential Targets for Medical Interventions. J. Amino Acids 2012, 2012, 1-26. [CrossRef]

29. Jones, D.P.; Park, Y.; Gletsu-Miller, N.; Liang, Y.; Yu, T.; Accardi, C.J.; Ziegler, T.R. Dietary sulfur amino acid effects on fasting plasma cysteine/cystine redox potential in humans. Nutrition 2011, 27, 199-205. [CrossRef]

30. Kazaks, A.; Collier, M.; Conley, M. Cytotoxicity of Caffeine on MCF-7 Cells Measured by XTT Cell Proliferation Assay (P06-038-19). Curr. Dev. Nutr. 2019, 3. [CrossRef]

31. Chatterjee, S.; Noack, H.; Possel, H.; Keilhoff, G.; Wolf, G. Glutathione levels in primary glial cultures: Monochlorobimane provides evidence of cell type-specific distribution. Glia 1999, 27, 152-161. [CrossRef]

32. Scherer, C.; Cristofanon, S.; Dicato, M.; Diederich, M. Homogeneous luminescence-based assay for quantifying the glutathione content in mammalian cells. Cells Nots 2008, 22, 7-9.

33. Tietze, F. Enzymic method for quantitative determination of nanogram amounts of total and oxidized glutathione: Applications to mammalian blood and other tissues. Anal. Biochem. 1969, 27, 502-522. [CrossRef]

34. Zhai, R.; Xue, X.; Zhang, L.; Yang, X.; Zhao, L.; Zhang, C. Strain-Specific Anti-inflammatory Properties of Two Akkermansia muciniphila Strains on Chronic Colitis in Mice. Front. Cell. Infect. Microbiol. 2019, 9, 239. [CrossRef]

35. Sinclair, J.L.; Barnes-Davies, M.; Kopp-Scheinpflug, C.; Forsythe, I.D. Strain-specific differences in the development of neuronal excitability in the mouse ventral nucleus of the trapezoid body. Hear. Res. 2017, 354, 28-37. [CrossRef]

36. Gooch, J.L.; Yee, D. Strain-specific differences in formation of apoptotic DNA ladders in MCF-7 breast cancer cells. Cancer Lett. 1999, 144, 31-37. [CrossRef]

37. Montesano, R.; Pepper, M.; Möhle-Steinlein, U.; Risau, W.; Wagner, E.; Orci, L. Increased proteolytic activity is responsible for the aberrant morphogenetic behavior of endothelial cells expressing the middle T oncogene. Cell 1990, 62, 435-445. [CrossRef]

38. Williams, R.L.; Risau, W.; Zerwes, H.-G.; Drexler, H.; Aguzzi, A.; Wagner, E.F. Endothelioma cells expressing the polyoma middle $\mathrm{T}$ oncogene induce hemangiomas by host cell recruitment. Cell 1989, 57, 1053-1063. [CrossRef]

39. Helms, H.C.; Abbott, N.J.; Burek, M.; Cecchelli, R.; Couraud, P.-O.; Deli, M.A.; Förster, C.; Galla, H.J.; Romero, I.A.; Shusta, E.V. In vitro models of the blood-brain barrier: An overview of commonly used brain endothelial cell culture models and guidelines for their use. J. Cereb. Blood Flow Metab. 2016, 36, 862-890. [CrossRef]

40. Yang, S.; Mei, S.; Jin, H.; Zhu, B.; Tian, Y.; Huo, J.; Cui, X.; Guo, A.; Zhao, Z. Identification of two immortalized cell lines, ECV304 and bEnd3, for in vitro permeability studies of blood-brain barrier. PLoS ONE 2017, 12, e0187017. [CrossRef]

41. Yang, T.; Roder, K.E.; Abbruscato, T.J. Evaluation of bEnd5 cell line as an in vitro model for the blood-brain barrier under normal and hypoxic/aglycemic conditions. J. Pharm. Sci. 2007, 96, 3196-3213. [CrossRef] [PubMed]

42. Agarwal, A.; Cho, C.-L.; Esteves, S.C.; Majzoub, A. Reactive oxygen species and sperm DNA fragmentation. Transl. Androl. Urol. 2017, 6, S695. [CrossRef] [PubMed]

43. Homa, S.T.; Vassiliou, A.M.; Stone, J.; Killeen, A.P.; Dawkins, A.; Xie, J.; Gould, F.; Ramsay, J.W. A comparison between two assays for measuring seminal oxidative stress and their relationship with sperm DNA fragmentation and semen parameters. Genes 2019, 10, 236. [CrossRef] 
44. Yuan, Y.; Zhang, J.; Wang, M.; Mei, B.; Guan, Y.; Liang, G. Detection of glutathione in vitro and in cells by the controlled self-assembly of nanorings. Anal. Chem. 2013, 85, 1280-1284. [CrossRef] [PubMed]

45. Cao, C.; Dai, L.; Mu, J.; Wang, X.; Hong, Y.; Zhu, C.; Jin, L.; Li, S. S1PR2 antagonist alleviates oxidative stress-enhanced brain endothelial permeability by attenuating p38 and Erk1/2-dependent cPLA2 phosphorylation. Cell. Signal. 2019, 53, 151-161. [CrossRef]

46. Song, J.; Kang, S.M.; Lee, W.T.; Park, K.A.; Lee, K.M.; Lee, J.E. Glutathione protects brain endothelial cells from hydrogen peroxide-induced oxidative stress by increasing nrf2 expression. Exp. Neurobiol. 2014, 23, 93-103. [CrossRef]

47. Bains, V.K.; Bains, R. The antioxidant master glutathione and periodontal health. Dent. Res. J. 2015, 12, 389-405. [CrossRef]

48. Kranner, I.; Birtić, S.; Anderson, K.M.; Pritchard, H.W. Glutathione half-cell reduction potential: A universal stress marker and modulator of programmed cell death? Free Radic. Biol. Med. 2006, 40, 2155-2165. [CrossRef]

49. Doroshow, J.H.; Juhasz, A. Modulation of selenium-dependent glutathione peroxidase activity enhances doxorubicin-induced apoptosis, tumour cell killing and hydroxyl radical production in human NCI/ADR-RES cancer cells despite high-level P-glycoprotein expression. Free Radic. Res. 2019, 53, 882-891. [CrossRef]

50. Shidara, K.; Mohan, G.; Lay, Y.-A.E.; Jepsen, K.J.; Yao, W.; Lane, N.E. Strain-specific differences in the development of bone loss and incidence of osteonecrosis following glucocorticoid treatment in two different mouse strains. J. Orthop. Transl. 2019, 16, 91-101. [CrossRef]

51. Sandberg, R.; Yasuda, R.; Pankratz, D.G.; Carter, T.A.; Del Rio, J.A.; Wodicka, L.; Mayford, M.; Lockhart, D.J.; Barlow, C. Regional and strain-specific gene expression mapping in the adult mouse brain. Proc. Natl. Acad. Sci. USA 2000, 97, 11038-11043. [CrossRef] [PubMed]

52. Cao, J.Y.; Poddar, A.; Magtanong, L.; Lumb, J.H.; Mileur, T.R.; Reid, M.A.; Dovey, C.M.; Wang, J.; Locasale, J.W.; Stone, E. A genome-wide haploid genetic screen identifies regulators of glutathione abundance and ferroptosis sensitivity. Cell Rep. 2019, 26, 1544-1556. [CrossRef] [PubMed]

53. Tanikawa, K.; Torimura, T. Studies on oxidative stress in liver diseases: Important future trends in liver research. Med. Mol. Morphol. 2006, 39, 22-27. [CrossRef] [PubMed]

54. Grasso, G.; Komatsu, H.; Axelsen, P. Covalent modifications of the amyloid beta peptide by hydroxynonenal: Effects on metal ion binding by monomers and insights into the fibril topology. J. Inorg. Biochem. 2017, 174, 130-136. [CrossRef]

55. Jaganjac, M.; Milkovic, L.; Gegotek, A.; Cindric, M.; Zarkovic, K.; Skrzydlewska, E.; Zarkovic, N. The relevance of pathophysiological alterations in redox signaling of 4-hydroxynonenal for pharmacological therapies of major stress-associated diseases. Free Radic. Biol. Med. 2019. [CrossRef] 